\title{
Metode Penginjilan Yesus Kristus Menurut Injil Lukas
}

\author{
Frans Wonatorei ${ }^{1}$, Marciano Antaricksawan Waani ${ }^{2}$ \\ 1, 2Pascasarjana Sekolah Tinggi Alkitab Jember, Jawa Timur \\ 1franswonatorei@gmail.com,2cianomar801@gmail.com
}

\begin{abstract}
Evangelism can be conveyed properly and correctly, when using methods. Jesus in Luke's gospel used various methods to be able to preach the gospel, with the aim that everyone who heard him could understand the gospel. This article uses a qualitative method with a literature study approach. The purpose of this research is that believers and pastors can preach the gospel using the methods that have been used by Jesus during His ministry on earth. The result of this research is that the evangelistic methods used by Jesus have various effects and make sinners know Jesus as Lord and Savior.
\end{abstract}

Keywords: evangelistic methods; evangelism of Jesus; Gospel of Luke

Abstrak. Penginjilan dapat tersampaikan dengan baik dan benar, bila menggunakan metode. Yesus dalam Injil Lukas menggunakan berbagai metode untuk bisa memberitakan Injil, dengan tujuan agar setiap orang yang mendengarkannya dapat memahami tentang Injil. Artikel ini menggunakan metode kualitatif dengan pendekatan studi literatur. Tujuan dari penelitian ini, agar orang-orang percaya serta para gembala dapat memberitakan injil dengan metode-metode yang telah dilakukan oleh Yesus pada masa pelayanan-Nya di dunia. Hasil dari penelitian ini, bahwa metode-metode penginjilan yang dipakai oleh Yesus menghasilkan berbagai dampak serta membuat orang berdosa mengenal Yesus sebagai Tuhan dan Juruselamat.

Kata kunci: Injil Lukas; metode penginjilan; penginjilan Yesus

\section{PENDAHULUAN}

Salah satu tugas gereja dan gembala adalah memberitakan injil serta menjadi terang dan garam bagi orang-orang berdosa. ${ }^{1}$ Tuhan Yesus acapkali menyatakan dalam pengajaranNya untuk melakukan penginjilan sampai ke ujung-ujung bumi, serta hidup menjadi terang dan garam. ${ }^{2}$ Pada masa pelayanan Yesus di dunia, Yesus menggunakan berbagai macam metode untuk memberitakan Injil, seperti: penginjilan pribadi; tanya jawab; visitasi; keteladanan disiplin rohani; kesaksian hidup, hal ini berimplikasi sehingga dalam pelayanan penginjilan, banyak mujizat dan tanda-tanda heran yang dilakuakan oleh Yesus, salah satu diantaranya; Yesus membangkitkan

${ }^{1}$ Paulus Purwoto, "Makna Proselitisasi Di Masa Intertestamental Bagi Misi," EPIGRAPHE: Jurnal Teologi dan Pelayanan Kristiani 4, no. 2 (2020): 251-263.

${ }^{2}$ Yonatan Alex Arifianto, Reni Triposa, and Daniel Supriyadi, "Menerapkan Matius 5: 13 Tentang Garam Dunia Di Tengah Era Disrupsi," SHAMAYIM: Jurnal Teologi dan Pendidikan Kristiani 1, no. 1 (2020): 92-106. 
anak muda di Nain (Luk. 7:11-17), kemudian, sebelum Yesus mengakhiri pelayanan penginjilan di dunia, dan naik kesorga, Ia memanggil kedua belas murid-Nya, lalu memberikan tenaga dan kuasa kepada mereka agar, dapat meneruskan misi penginjilan ini (Luk. 9:1-6). Yesus telah melakukan semua tindakan penginjilan bahkan menjadikan diri-Nya sebagai teladan untuk murid-murid-Nya agar bisa melanjutkan penginjilan ke seluruh dunia. ${ }^{3}$

Setelah Yesus naik ke surga, maka gereja menjadi alat Tuhan untuk melakukan penginjilan ke seluruh dunia. Gereja tidak bisa menghindar dari kenyataan tersebut bahwa identitas gereja ialah melakukan penginjilan dan memberitakan kerajaan Allah. Dengan demikian orang percaya (gembala) sudah harus menyadari akan panggilan dan tanggung jawab sebagai pemegang mandat Allah di bumi, dalam mengembangkan misi pelayanan penginjilan yang ditinggalkan oleh Yesus Kristus.

Gembala harus berpikir kritis dalam menanggapi perintah Tuhan Yesus dengan merencangkan strategi, cara/metode yang efektif bagi pelayanan penginjilan agar memenangkan jiwa bagi Kristus. Untuk itu tugas Penginjilan jangan sampai diabaikan, karena tugas ini merupakan tugas utama yang diberikan Yesus Kristus sebelum Dia naik ke surga kepada gereja dan harus dilaksanakan. ${ }^{4}$ Fungsi Gereja tidak hanya mengerjakan pelayanan ke dalam saja, seperti fungsi leiturgia, artinya melaksanakan fungsi pengudusan; fungsi kerygma, yaitu melaksanakan fungsi pemberitaan kabar baik; pendalaman Firman Allah; fungsi koinonia, yaitu melaksanakan fungsi persekutuan, pujian dan penyembahan kepada Tuhan; fungsi marturia, yaitu melaksanakan fungsi kesaksian, menjadi saksi dan bersaksi dengan cara hidup yang benar dalam kebenaran, dan fungsi diakonia, yaitu melaksanakan pelayanan sosial. Namun, gereja juga memiliki fungsi untuk melaksanakan pelayanan ke luar, yaitu penginjilan, mengabarkan Injil agar direspon orang berdosa. Tuhan Yesus, semasa pelayanan-Nya memberi teladan tentang tugas ini, dan ketika naik ke surga Ia memberi pesan Amanat Agung untuk terus dikerjakan oleh setiap orang yang percaya (Mat. 28:1920). 5 Tantangan terbesar yang dihadapi gereja sejak zaman dahulu sampai saat ini adalah bagaimana membuat Kristus dikenal dan diterima oleh setiap orang.

Penginjilan harus ditempatkan sebagai prioritas yang tinggi bagi semua orang percaya, bahwa Yesus Kristus adalah Allah dari segalanya. Keselamatan tidak ada di dalam siapa pun juga selain di dalam Dia, sebab di bawah kolong langit ini tidak ada

${ }^{3}$ Alfons Renaldo Tampenawas, Erna Ngala, and Maria Taliwuna, "Teladan Tuhan Yesus Menurut Injil Matius Dan Implementasinya Bagi Guru Kristen Masa Kini," EDULEAD: Journal of Christian Education and Leadership 1, no. 2 (2020): 214-231.

${ }^{4}$ Kristian Badai, Kaleb Djeremod, and Frets Keriapy, "Penginjilan Sebagai Upaya Meneguhkan Keyakinan Keselamatan Anak," HARVESTER: Jurnal Teologi dan Kepemimpinan Kristen 5, no. 2 (2020): 120-134. Band. Fransiskus Irwan Widjaja, Daniel Ginting, and Sabar Manahan Hutagalung, "Teologi Misi Sebagai Teologi Amanat Agung," THRONOS: Jurnal Teologi Kristen 1, no. 1 (2019): 17-24.

5Susanto Dwiraharjo, “Kajian Eksegetikal Amanat Agung Menurut Matius 28 : 18-20," Jurnal Teologi Gracia Deo 1, no. 2 (2019): 56-73, http://sttbaptisjkt.ac.id/e-journal/index.php/graciadeo. Band. Handreas Hartono, "Mengaktualisasikan Amanat Agung Matius 28: 19-20 Dalam Konteks Era Digital," KURIOS (Jurnal Teologi dan Pendidikan Agama Kristen) 4, no. 2 (2018): 157-166. 
nama lain yang diberikan kepada manusia yang olehnya kita dapat diselamatkan (Kis. 4:12). Sepanjang sejarah dunia, pergumulan utama manusia adalah tentang keselamatan atau kehidupan kekal. Dari Alkitab manusia dapat mengetahui berita keselamatan hanya di dalam Yesus Kristus (Kis. 4:12). Hal ini telah dibuktikan bahwa Yesus sepanjang hidup-Nya di dunia memberitakan Injil kerajaan Allah, dan memberi hidup-Nya sendiri sebagai inti berita keselamatan itu. Setelah Yesus naik ke Sorga Ia telah mendelegasikan tugas pelaksanaan misi penginjilan kepada para murid-Nya; hingga kini penginjilan terus berlangsung di seluruh dunia sesuai perintah-Nya (Kis. 1:8). Pelaksanaan penginjilan dan pendidikan Jemaat bertumbuh dewasa di dalam Kristus dilakukan oleh para rasul, nabi, penginjil, gembala dan guru, sesuai karunianya masing-masing (Ef. 4:1-13).

Gereja adalah sebagai pelopor misi penginjilan dunia, jadi pemimpin dalam setiap gereja lokal adalah pelaksana amanat agung Yesus Kristus. Substansi dari amanat agung adalah menjadikan semua bangsa murid Kritus, dengan metode pergi memberitakan Injil kepada semua bangsa, semua golongan, semua suku di dunia ini. ${ }^{6}$ pergi untuk memberitakan Injil keselamatan di dalam Yesus Kristus, inti beritanya adalah Yesus yang telah lahir melayani sebagai Mesias, hidup, mati, bangkit, dan naik ke surga, dan yang akan datang kembali sebagai Hakim yang adil bagi semua orang. ${ }^{7}$ Gereja tidak hanya pergi tetapi juga membaptis semua orang yang telah menerima Injil, dengan baptisan air sebagai lambang dimasukkannya ke dalam pesekutuan dengan Kristus sebagai manusia baru. Tidak hanya berhenti setelah dibaptis tetapi dilanjutkan dengan mengajarkan semua kebenaran Firman Allah dan mentaatinya sehingga bisa menjadi murid Kristus yang hidup dalam kebenaran Firman Tuhan. ${ }^{8}$

George Verwer mengutip dari Charles Swindoll mengatakan:

Orang Kristen diselamatkan oleh iman, melalui pengorbanan dan kematian Yesus di salib. Dan bahwa tidak ada satupun dari milik kita yang layak untuk dipersembahkan kepada-Nya sebagai imbalan. Kita hanya menerima begitu saja sebagai hadiah cuma-cuma yang Dia anugerahkan kepada kita dalam kemurahanNya. Sekali kita mengerti makna 'anugerah'vertikal dari salib sebagai hadiah tanpa harus dibayar dari Allah, maka anugerah horizontal yang kita teruskan kepada oarang lain secara otomatis akan mengenai sasaran. ${ }^{9}$

Aktifitas penginjilan yang dilakukan para Gembala Sidang adalah sebagai wujud nyata melaksanakan Amanat Agung Tuhan Yesus, mandat spiritual dan mandat budaya sama seperti melayani rohani dan jasmani.

Peter Wongso menuliskan, "Pekerjaan pemberitaan Injil adalah urusan seluruh gereja, bukan merupakan sandiwara bagi beberapa orang, hal ini juga merupakan

\footnotetext{
6Susanto Dwiraharjo, “Kajian Eksegetikal Amanat Agung Menurut Matius 28: 18-20,” Jurnal Teologi Gracia Deo 1, no. 2 (2019): 56-73.

${ }^{7}$ Yosua Feliciano Camerling and Hengki Wijaya, "Misi Dan Kebangkitan Rohani: Implikasi Misi Allah Bagi Gereja," Jurnal Ilmiah Religiosity Entity Humanity (JIREH) 1, no. 1 (2019): 57-71.

${ }^{8}$ Dorce Sondopen, "Relasi Antara Penginjilan Dan Pemuridan Untuk Pertumbuhan Gereja," Excelsis Deo: Jurnal Teologi, Misiologi, dan Pendidikan 3, no. 2 (2019): 95-105.

${ }^{9}$ George Verwer, Melangkah Keluar Dari Kenyamanan Dunia (Yayasan Obor Mitra, 2001).
} 
suatu investasi di dalam proyek yang paling berharga dan mencurahkan segala modal yang ada di dalam gereja baik berupa tenaga-tenaga berbakat maupun kekayaan materi."10 Artinya, gereja merupakan sebuah wadah atau institusi dalam kegiatan penginjilan kepada setiap unsur manusia, karena penginjilan adalah tanggung jawab gereja terhadap Tuhan yang tidak bisa diabaikan.

Penelitian sebelumnya mengenai metode penginjilan Yesus Kristus pernah dilakukan oleh Harming yang mengkaji metode penginjilan Yesus dengan berfokus pada Injil Yohanes 4:1-42, dengan kesimpulan bahwa Metode penginjilan dari Yesus Kristus adalah metode dengan pendekatan lintas budaya atau multicultural. ${ }^{11}$ Maka berbeda dari penelitian sebelumnya oleh Harming, pada penelitian ini peneliti memfokuskan kajian metode penginjilan Yesus Kristus menurut Injil Lukas dengan tujuan untuk menemukan metode penginjilan yang bisa digunakan oleh para hamba Tuhan masa kini, sehingga injil bisa diberitakan keseluruh dunia.

\section{METODE PENELITIAN}

Artikel ini menggunakan pendekatan kualitatif dengan metode kajian pustaka. Pendekatan kualitatif merupkan suatu proses penelitian dan pemahaman yang berdasarkan pada metodologi yang menyelidiki suatu fenomena sosial dan masalah manusia. Pada penelitian ini peneliti membuat suatu gambaran kompleks, meneliti kata-kata, laporan terinci dari pandangan responden dan melakukan studi pada situasi yang dialami. ${ }^{12}$ Berdasarkan masalah-masalah actual, maka penulis meneliti bagaimana peran gembala jemaat dan aplikasinya dalam misi penginjilan. Sebagaimana penelitian kualitatif yang akan dilaksankan, bersifat tentatif, sebab dimungkinkan akan mengalami perkembangan atau perubahan dari hipotesis awal penulis.

\section{PEMBAHASAN}

\section{Metode Penginjilan Yesus}

Metode dalam Kamus Umum Bahasa Indonesia artinya: "Cara yang telah teratur dan berpikir baik-baik untuk mencapai sesuatu maksud"13. Pelaksanaan penginjilan jika ingin efektif tentunya harus memakai metode-metode penginjilan yang disesuaikan dengan situasi dan kondisi lapangan. Penggunaan metode dalam penginjilan tidaklah bertentangan dengan pekerjaan Roh Kudus. Bagus Surjantoro mengemukakan: "Mengikuti kegerakan Roh Kudus juga berarti berhikmat dan peka mengikuti metode-metode Allah yang berkembang sesuai dengan perjalanan zaman dan waktu tanpa mengurangi keutuhan Injil. Belum tentu cara yang efektif kita pakai pada tahun 1980-an akan sama efektifnya bila diterapkan sekarang. Belum tentu juga cara yang berhasil di tempat A akan bisa dipakai efektif di tempat B. Pepatah kuno

\footnotetext{
${ }^{10}$ Peter Wongso, Tugas Gereja Masa Kini (Surabaya: Yakin, 1991).

${ }^{11}$ Harming Harming, "Metode Penginjilan Yesus Dalam Injil Yohanes 4: 1-42," Evangelikal 1, no. 2 (2017): 162-169.

${ }^{12}$ John Chresswell, Research Design: Qualitative and Quantitative Approaches (Thousand Ouks: Sage Publication, 1990), 15.

${ }^{13}$ Kemdikbud, "Kamus Besar Bahasa Indonesia (KBBI)."
} 
mengatakan: "lain padang lain belalang, lain lubuk lain ikannya." Namun, prinsipprinsip Alkitab tidak akan pernah berubah dan rencana Allah untuk keselamatan dunia tidak pernah diralat atau diubah. Dinamika pekerjaan Roh kudus tidak pernah kaku dengan satu metode tertentu atau tradisi tertentu"14.

\section{Penginjilan Pribadi}

Pertama, Tuhan Yesus menjumpai seseorang untuk memberitakan kerajaan Sorga, metode kesaksian dalam pemberitaan Injil terdapat dalam Injil Lukas. Inti berita Injil yang dilakukan Yesus adalah tentang kerajaan sorga atau kerajaan Allah. Artinya, berita tentang bagaimana Allah memerintah dalam hidup orang percaya. Tuhan Yesus tidak hanya menunggu orang berdosa datang kepadaNya tetapi Ia mencari orang berdosa sebagaimana yang Yesus lakukan bagi para pemungut cukai, Ia datang menjumpai mereka secara pribadi. ${ }^{15}$ Ia mencari dan menyelamatkan yang terhilang, seperti yang diungkapkan dalam Lukas 19:10, "Sebab Anak Manusia datang untuk mencari dan menyelamatkan yang hilang." Hal serupa juga disebutkan dalam Kisah Para Rasul 1:8, “...dan kamu akan menjadi saksiKu di Yerusalem dan di seluruh Yudea dan Samaria dan sampai ke ujung bumi."

Selanjutnya, Bagus Surjanto menjelaskan pengertian tentang kata saksi, mengatakan,

orang percaya diberikan kuasa Roh Kudus untuk menjadi saksi Tuhan, Kata 'saksi' dalam ayat ini adalah martureo yang artinya, bersaksi. Dari kata inilah kita mengenal istilah marturia. Bersaksi bukanlah berarti menjadi pengkhotbah atau pendeta walaupun itu merupakan salah satu bentuk dari kesaksian. Bersaksilah adalah seluruh totalitas hidup kita me-lalui perkataan dan perbuatan. Bersaksi melalui perbuatan seringkali berbicara jauh lebih keras daripada perkataan kita. Bersaksi bisa juga berarti mengatakan dan menjadi saksi ma-ta kebenaran Kristus, pribadi dan karya-Nya sehingga dunia benar-benar meng-aminkan kebenaran itu. ${ }^{16}$

Kedua, Tuhan Yesus memberikan perhatian kepada pribadi yang berdosa untuk diselamatkan melalui kasih-Nya. ${ }^{17}$ Penginjilan adalah fokus kepada orang berdosa yang perlu diselamatkan. ${ }^{18}$ Yesus mengasihi semua orang berdosa, tetapi Yesus membenci dosa. Jadi perhatian-Nya penuh terhadap orang orang yang menjadi sasaran penginjilan. Tidak seorangpun dapat datang kepada Allah kalau tidak dicari dan ditemui oleh Yesus. Mereka yang percaya akan diselamatkan. Yesus membuktikan perhatiannya kepda orang orang yang menderita, kesusahan, kesedihan, kelaparan, penyakit, juga kematian. Dalam Lukas 6:17-26 Yesus mengajar dan menyembuhkan orang banyak; selain menyembuhkan hamba perwira di Kapernaum (7:1-9); mem-

\footnotetext{
${ }^{14}$ Bagus Surjantoro, Hati Misi (Yogyakarta: ANDI, 2006).

${ }^{15}$ Hannas Hannas and Rinawaty Rinawaty, "Menerapkan Model Penginjilan Pada Masa Kini," KURIOS (Jurnal Teologi dan Pendidikan Agama Kristen) 5, no. 2 (2019): 175-189.

${ }^{16}$ Bagus Surjantoro, Misi Dari Dalam Krisis (Jakarta: Obor Mitra Indonesia, 2001).

${ }^{17}$ Febriaman Lalaziduhu Harefa, "Menggunakan Konsep Inkarnasi Yesus Sebagai Model Penginjilan Multikultural," PASCA: Jurnal Teologi dan Pendidikan Agama Kristen 16, no. 1 (2020): 5061.

${ }^{18}$ Fransiskus Irwan Widjaja, Misiologi Antara Teori, Fakta Dan Pengalaman, 1st ed. (Yogyakarta: Andi Offset, 2018).
} 
bangkitkan anak muda di Nain (7:11-17); menyembuhkan orang kerasukan setan di Gerasa (8:26-38). Yesus menyembuhkan mereka, menghibur mereka, membangkitkan yang mati. Namun bukan itu yang menjadi sasaran penginjilan Yesus, melainkan hidup dibalik kematian adalah kehidupan yang kekal. Disela-sela perbuatan mujizat yang dilakukan Yesus, Dia selalu memberitakan kerajaan Allah. Pembebasan dari segala perbudakan adalah fokus perhatian Yesus terhadap orang banyak. Demikian setiap misionaris atau pendeta masa kini wajib memberikan perhatian khusus terhadap jiwa-jiwa yang terhilang.

Ketiga, Tuhan Yesus menyembuhkan penyakit secara perorangan dalam perjalanan misi-Nya. Yesus berurusan dengan pribadi pribadi orang berdosa. Ia peduli terhadap semua kebutuhan manusia. Ia selalu bersentuhan dengan orang perorang secara pribadi dalam penginjilan-Nya. Sangat banyak mujizat dilakukan Yesus bagi orang yang menderita karena penyakit. Berita kerajaan Allah yang diajarkan Yesus, bukan hanya berita secara verbal tepai fakta Ia menyembuhkan penyakit, menghibur yang susah, membebaskan yang kerasukan setan. Dalam penginjilan yang dilakukan Yesus Ia melakukan banyak mujizat, demiian pula orang percaya dapat menteladani Kristus dalam pelayanannya. Memohon pertolongan Tuhan, agar pelayanan dapat disertai dengan berbagai karunia Roh Kudus (Band. Luk. 11:20).

Keempat, Tuhan Yesus mendoakan pribadi-pribadi muridNya dan orang lain. Salah satu contoh sikap yang baik dari Tuhan Yesus dalam aktivitas penginjilan-Nya adalah sebagai seorang pendoa yang tekun dan disiplin. ${ }^{19}$ Kunci keberhasilan penginjilan adalah doa. Doa merupakan komunikasi yang intim dengan Tuhan, hal tersebut dilakukan Yesus dalam pelayan-Nya. ${ }^{20}$ Dalam komunikasi ini Yesus telah menjadi teladan yang sempurna. Ia adalah Anak Allah yang turun dari surga, tahu bahwa diriNya diutus oleh Bapa, untk menjadi penebus dosa dunia, yang dalam pelaksanaan misi-Nya di dunia banyak mengalami tantangan dan penderitaan. Ia begitu mengasihi manusia berdosa, namun Ia masih memeohon pertolongan Bapa di Sorga. Bahkan Yesus membutuhkan Roh Kudus menyertai pelayanan-Nya. Dalam hal inilah setiap orang percaya patut mengikuti jejak Yesus. Dalam menghadapi penginjilan pribadi, perlu persiapan dengan doa bagi orang-orang yang menjadi target Injil, agar Tuhan menolong dan proses penginjilan berjalan dengan baik.

Kelima, Tuhan Yesus mengusir setan secara perseorangan. Dalam Injil Lukas terdapat banyak mujizat dilakukan Yesus termasuk mengusir setan secara perseorangan. Tantangan bagi setiap penginjil adalah bagaiamana ia dapat menginjil dengan efektif dengan diserttai berbagai karunia Roh Kudus, termasuk karunia membedakan Roh dan karunia mujizat. Roh Kudus adalah mitra kerja yang efektif bagi penginjil dalam melaksanakan misi Allah di ladang misi.

\footnotetext{
${ }^{19}$ Johannis Siahaya, “Misi Dalam Doa Yesus Menurut Yohanes 17," Jurnal Teruna Bhakti 1, no. 2 (2019): 19-20, http://e-journal.stakterunabhakti.ac.id/index.php/teruna/issue/archive.

${ }^{20}$ Bertha Tarigan, "Konsep Doa Yesus Kristus Menurut Yohanes 17: 1-26," KERUGMA: Jurnal Teologi dan Pendidikan Agama Kristen 1, no. 2 (2019): 110-121.
} 
Para penginjil juga diberikan kuasa untuk mengusir setan; mereka diurapi dan diutus untuk menyembuhkan penyakit, dan mengusir setan, di samping memberitakan Injil. Setiap orang yang percaya kepada Yesus akan diberi kuasa untuk mengusir setan. ${ }^{21}$ Berita Injil mendapat peneguhan memelui berbagai penyataan karunia Roh Kudus dimana misionaris pergi melayani. Lukas 11:18 menyebutkan, "Jikalau Iblis itu juga terbagi-bagi dan melawan dirinya sendiri, bagaimanakah kerajaannya dapat bertahan?" Dan lebih lanjut memberikan penegasan, "Jadi jika Aku mengusir setan dengan kuasa Beelzebul, dengan kuasa apakah pengikut-pengikutmu mengusirnya?" Pengusiran setan menandakan kehadiran kuasa Allah, pernyataan kerajaan Allah (Luk. 11:20).

Keenam, Tuhan Yesus menerima seseorang yang datang secara pribadi meminta pertolongan kepada-Nya. Terdapat banyak kasus dalam kitab Injil dimana Yesus didatangi orang orang yang membutuhkan pertolongan-Nya. Lukas 7:1-9 menceritakan tentang perwira yang membutuhkan mujizat bagi hambanya; di tempat lain memberi makan lima ribu orang yang kelaparan (Luk. 8:10-16). Lukas 18:35-43 menceritakan tentang Yesus yang menyembuhkan orang buta di dekat Yerikho. Ini adalah sebagian contoh bahwa dalam penginjilan pribadi seorang misionaris memerlukan kuasa Allah dalam Roh Kudus untuk menyertainya agar dapat melayani jiwa jiwa dengan dengan baik ${ }^{22}$; penuh kasih dan kuasa. Pelayanan dengan kuasa adalah ciri pelayan penginjilan Yesus yang tiada taranya. Misionaris di abad ini perlu kembali kepada metode Yesus dalam melaksanakan misi penginjilan.

\section{Tanya-Jawab}

Metode yang sering dipakai Yesus dalam pelayanan adalah metode tanya jawab. Pada pelayanan Yesus kerap kali mengajukan pertanyaan-pertanyaan kepada para pendengar-Nya. Hal ini dimaksudkan oleh Yesus untuk memperoleh tanggapan dari para pendengar-Nya tentang suatu pengajaran yang hendak disampaikan Yesus. Dengan kata lain bahwa Yesus dengan jalan bertanya denga maksud para pendengarNya memberi jawaban maka akan terjadi komunikasi secara bertanggapan.

Pada bagian ini peneliti hendak mengemukanakan empat hal penting yang diperhatikan, yaitu Tuhan Yesus melakukan tanya-jawab dalam mengajar kebenaran. Ia sanggup menjawab dengan benar dan tegas dan memuaskan pertanyaan penanya tentang kehidupan kekal. Dalam memulai tanya-jawab, Yesus menampilkan diri sebagai sosok guru yang bijaksana yang dapt membuka pikitan murid untuk memahami kebenaran; pemberitaan Injil melalui tanya-jawab berarti dengan membangun komunikasi persahabatan yang erat.

Pertama, Tuhan Yesus melakukan tanya-jawab dalam mengajar kebenaran. Penggunaan metode tanya-jawab oleh Yesus dimaksudkan agar para pendengar-Nya

\footnotetext{
${ }^{21}$ Jonidius Illu, “PEnGUSIRAN SETAN," Phronesis: Jurnal Teologi dan Misi 3, no. 2 (2020): 158169.

${ }^{22}$ Asih Rachmani Endang Sumiwi, "Peran Roh Kudus Dalam Kehidupan Orang Percaya Masa Kini," Jurnal Teologi Gracia Deo 1, no. 1 (2018): 23-31.
} 
belajar berpikir secara aktif dan belajar mengemukakan pendapat tentang sesuatu kebenaran, dengan demikian ada komunikasi timbal balik. Selain itu, melalui pertanyaan yang diajukan, Yesus sedang membuka pemikiran bagi para pendengar-Nya untuk dipikirkan dan diberi jawaban atasnya. Heinz Kock memberikan komentar "Dengan pertanyaan guru, seorang murid didorong untuk berpikir, murid mempelajari cara memecahkan masalah murid belajar secara aktif sebab mereka harus berpikir untuk menjawab pertanyaan guru."23

Hal senada diungkapkan oleh Edi Tanya,

Teknik bertukar pikiran dalam ber-bagai bentuk seperti diskusi, tanya-jawab dapat memberi rangsangan timbal balik di antara anggota-anggota dalam kelompok yang membawa dampak kepada pikiran, emosi dan kepribadian mereka itulah sebabnya bertukar pikiran itu dapat menjadi komunikasi Injil dan persekutuan Injil. Dengan sangat bijaksana Yesus menggunakan metode tanya jawab untuk mencapai maksud dan tujuan pelayanan-Nya. ${ }^{24}$

Dalam kitab-kitab Injil terdapat sangat banyak pertanyaan-pertanyaan yang diajukan Yesus kepada para pendengarNya. Dalam setiap bentuk pelayanan Yesus, secara khusus pada waktu Ia melayani orang-orang sakit, secara umum mendahului tindakan penyembuhan, Yesus selalu mengajukan pertanyaan-pertanyaan kepada orang sakit itu. B. Fobia, menyebutkan, "Cara bertanya menjadi ciri tersendiri dari cerita-cerita keajaiban yang biasanya mendahului atau menyusuli tindakan ajaib dari pahlawan atau tokoh Ilahi, yang dalam hal ini adalah Yesus, dengan demikian menonjol Yesus sebagai pembuat mujizat."25

Jadi, secara singkat dapat dimengerti bahwa pemakaian metode tanya jawab dalam pelayanan Yesus merupakan satu metode yang sangat efektif. Dalam bagian ini tentunya tidak dimaksudkan untuk mendaftarkan seluruh pertanyaan Yesus kepada para pendengar-Nya. Salah satu contoh metode bertanya yang paling dikenal ketika Yesus bertanya kepada para murid-Nya tentang diri-Nya, "Menurut pendapatmu siapakah Aku ini?" (Mat. 16:15). Melalui pertanyaan ini sebenarnya Yesus ingin agar murid-murid memberikan tanggapannya, memberikan penjelasan tentang imannya, atau mengungkapkan afirmasi-afirmasi, pengakuan iman kepada Yesus. Pertanyaan Yesus mendapatkan tanggapan yang serius oleh Petrus dan dengan keyakinan yang matang Petrus mengungkapkan pengakuan imannya bahwa "Engkau adalah Mesias, Anak Allah yang hidup" (Mat. 16:16); Mesias berarti yang diurapi. Jadi, menurut pengakuan Petrus, Yesus adalah 'unik', dan merupakan pusat yang mutlak dalam pekerjaan anugerah yang Allah kerjakan di dunia ini. Hal inilah yang menjadi keyakinan Petrus, bahwa pengakuannya bukan hal yang biasa, oleh karena Yesus tidak sama dengan Mesias yang dinantikan Yahudi, mereka menantikan Mesias sebagai raja yang langsung memusnahkan musuh-musuh israel."26

\footnotetext{
${ }^{23}$ Heinz Kock, Sang Guru Yang Baik (Yogyakarta: kanisius, 1986).

${ }^{24}$ Edi Tanya, Gereja Dan Pendidikan Agama Kristen (Cianjur: STT Cipanas, 1999).

${ }^{25}$ B. Fobia, "Yesus Dan Badai Laut" (1997).

${ }^{26}$ J.J de Heer, Tafsiran Alkitab Injil Matius Pasal 1-22 (Jakarta: BPK Gunung Mulia, 1991).
} 
Kedua, Tuhan Yesus sanggup menjawab dengan benar dan memuaskan semua pertanyaan para penanya tentang kehidupan kekal. Dengan kata lain, sering ditemukan rentetan pertanyaan baru dari Yesus sebagai tanggapanNya atas pertanyaan sebelumnya. Dalam hal inilah memunculkan suatu dialog antara Yesus dengan lawan bicara-Nya. Contoh untuk bagian ini misalnya pada saat terjadi dialog antara Yesus dengan seorang muda kaya, yang bertanya tentang kehidupan kekal (Luk. 18:18-27). Tanya-jawab yang terjadi dalam hal ini sebenarnya dimaksudkan oleh Yesus untuk menuntun pemuda ini kepada kebenaran. Ketika pemuda kaya mengajukan pertanyaannya, Yesus tidak langsung memberikan jawaban-Nya, melainkan Ia bertanya kembali sebagai tanggapan-Nya.

Robert E. Boehlke dalam sebuah bukunya menyebutkan demikian: "Seorang muda kaya datang kepada Yesus, pada setiap tahap pertukar pikiran yang terjadi, sipemuda kaya itu diantar untuk menggali lebih dalam lagi, sampai pada akhirnya ia tidak rela menerima hasil penggalian itu"27 Dalam hal ini belajar dari metode ini Yesus menjadi teladan yang sempurna dalam menjelaskan berbagai pertanyaan yang sulit, meskipun diajukan oleh seorang terpelajar, kaya, dan berpengetahuan agama yang tinggi. Dalam hal ini Yesus menunjukkan bahwa Ia adalah guru yang agung, memberikan penjelasan yang tepat .

Ketiga, Yesus dapat membuka pikiran murid untuk memahami kebenaran. Dalam Lukas 24:13-35 ada fakta penting di mana Yesus menyatakan diri kepada dua murid yang sedang berjalan menuju Emaus. Yesus tidak terburu-buru memperkenalkan diri-Nya, tetapi Ia mendekati murid-murid-Nya, bergaul dengan mereka yang dalam keadaan bingung. Murid ini sedang galau sebab mereka tidak mengerti bagaimana seorang baik seperti Yesus dibunuh dan disalibkan oleh bangsanya. Yesus mengetahui kegalauan mereka, merekapun tidak mengenal Yesus yang sedang bersama mereka, cara Yesus membuka pikiran mereka melalui proses tanya jawab. Yesus memulai dengan pertanyaan diagnosa. Dalam dialog itu, pada ayat 16, Yesus juga bertanya lagi: Apakah itu? Di ayat 19 Yesus membiarkan murid itu terus menjelaskan apa yang mereka sedang pikirkan. Kemudian Yesus mulai berkata, "hai kamu orang bodoh" betapa lambannya hatimu, sehingga kamu tidak percaya segala sesuatu, yang telah dikatakan para nabi. percakapan itu berlanjut, akhirnya murid itu mulai mengenal Yesus sendiri yang sedang diperbincangkan selama di perjalanan. Metode tanya-jawab seperti ini relevan dalam penyampaian berita Injil. Melihat pergumulan orang berdosa dan membawa mereka dengan cara bijaksana kepada Tuhan Yesus.

\section{Visitasi}

Dari antara sekian banyak metode penginnjilan Yesus, salah satunya ialah metode visitasi. Metode ini artinya Yesus berkunjung ke sasaran misi. Ada tiga hal yang dapat diuraikan pada bagian ini yaitu: kedatangan Yesus ke dunia merupakan kun-

\footnotetext{
${ }^{27}$ Robert E.Boehlke, Sejarah Perkembangan Pikiran Dan Pendidikan Agama Kristen (Jakarta: BPK Gunung Mulia, 1991).
} 
jungan Allah kepada manusia berdosa; Tuhan Yesus melakukan penginjilan dengan mengunjungi sasaran-Nya; Yesus tidak hanya menunggu orang datang kepadaNya , tetapi Ia pergi mencari yang terhilang.

Pertama, Kedatangan Yesus kedunia merupakan kunjungan Allah kepada manusia berdosa. Artinya Kehadiran Yesus ditengah dunia, adalah bukti kedatangan Allah kepada manusia, atau perkunjungan Allah dari Sorga ke dalam dunia. Ia tidak hanya mendatangi seluruh umat manusia di suatu tempat tetapi Ia bermaksud untuk menjumpai setiap manusia di semua tempat dan semua waktu. Allah tidak memakai malaikat untuk memberitakan Injil, tetapi memakai semua orang percaya, orang percaya yang diutus dengan kuasa Roh Kudus pergi memberitakan Injil ${ }^{28}$. Perkunjungan Allah kedunia dari Sorga yang mulia adalah penting mengajarkan kepada orang percaya bahwa perkunjungan misionaris ke seluruh dunia menjangkau orang berdosa bagi Kristus adalah hal yang urgen.

Kedua, Tuhan Yesus melakukan penginjilan dengan mengunjungi sasaran-Nya. Pada dasarnya Allah memiliki sifat yang sangat pribadi hendak menjumpai setiap manusia secara pribadi. Setelah manuisa jatuh kedalam dosa Tindakan Allah adalah datang dan mencari manusia secara langsung. ${ }^{29}$ Tiap orang harus berjumpa dengan Yesus secara pribadi; oleh karena itu, para murid Yesus atau orang percaya harus mengambil sikap untuk selalu dapat mendatangi sasaran yang hendak disampaikan berita Injil. Ada banyak penginjilan yang Yesus lakukan dengan cara perkunjungan dari rumah ke rumah.

\section{Keteladanan Disiplin Rohani}

Ada beberapa hal mengenai teladan yang dapat dilihat dari pribadi Yesus, yaitu teladan dalam penderitaan, tidak berbuat dosa, tidak pernah menipu, tidak membalas pada saat dicaci maki, sabar dalam ancaman, penyerahan diri total pada kehendak Allah, teladan dalam kebenaran. Mengenai teladan dalam penderitaan, Alkitab menyebutkan teladan itu, "sebab untuk itulah kamu dipanggil, karena Kristus pun telah menderita untuk kamu dan telah meninggalkan teladan bagimu supaya kamu mengikuti jejak-Nya (1Pet. 2:21). Penegasan Yesus jelas, “...Setiap orang yang mau mengikuti Aku, ia harus menyangkal dirinya, memikul salib dan mengikut Aku." Yesus telah menunjukkan bahwa Ia telah menerima penderitaan. Yesus menderita lebih dari siapa pun, dan Ia telah menunjukkan kasih-Nya kepada semua orang berdosa. ${ }^{30}$ Penderitaan Yesus menunjukkan betapa besar kasihNya bagi orang-orang berdosa. ${ }^{31}$ Lukas 24:26 juga mengatakan dengan gamblang, "Bukankah Mesias harus

\footnotetext{
${ }^{28}$ Daniel Sutoyo, "Peran Roh Kudus Dalam Pemberitaan Injil," Jurnal Antusias, vol. 1, (2011), accessed April 27, 2017, http://www.sttintheos.ac.id/e-journal/index.php/antusias/article/view/1.

${ }^{29}$ Widjaja, Ginting, and Hutagalung, "Teologi Misi Sebagai Teologi Amanat Agung."

${ }^{30}$ Meldayanti Berutu, "Makna Penderitaan Yesus Di Kayu Salib (Eksegetis Lukas 23: 33-43) Dan Refleksinya Bagi Umat Kristen Masa Kini," Areopagus: Jurnal Pendidikan Dan Teologi Kristen 18, no. 2 (2020): 76-83.

${ }^{31}$ Lewi Nataniel Bora, "Keserupaan Dengan Yesus Dalam Penderitaan, Kesengsaraan Dan Kematian-Nya," Manna Rafflesia 7, no. 1 (2020): 65-89.
} 
menderita semuanya itu untuk masuk ke dalam kemuliaan-Nya?"

Yesus tidak berdosa; Petrus menegaskan hal itu, "Ia tidak berbuat dosa dan tipu tidak ada dalam mulut-Nya" (1Pet. 2:22). Yesus tidak pernah membalas ketika dicacimaki; justru Ia mengajarakan, “...kasihilah musuhmu dan berdoalah bagi mereka yang menganiaya kamu...” (Mat. 5:44-45). Hal tidak membalas caci maki merupakan hal yang paling berat untuk dilakukan sebagai umat manusia. sebagai manusia biasa kita selalu tergoda untuk membalas segala sakit hati kepada mereka. namun dengan keteguhan dan ketekunan hati, Yesus telah merubah sakit hati tersebut menjadi kebahagiaan yang utuh tak kurang suatu apapun melalui satu ujian (ujian kerendahan hati). Yesus tetap sabar sekalipun dalam ancaman (band. Luk. 21:19; Rm. 12:12;). Teladan bersabar di dalam ancaman merupakan esensi dalam ajaran Kristen, di mana Yesus menunjukkan kasih-Nya kepada musuh-Nya dan kehidupan yang dijanjikanNya adalah kehidupan kekal. Yesus meneladankan tentang menyerahkan segala hal kepada Allah.

Yesus memberikan keteladanan tentang kebenaran dalam Iman. Penebusan dosa yang dilakukan Yesus adalah inti kebenaran pengajaran-Nya; kebenaran yang mutlak, kebenaran yang tidak terbantahkan supaya kita sebagai umat Kristen tidak sia-sia mempercayai Yesus adalah juru selamat manusia dan kita menerima anugerah keselamatan abadi dan bukan kematian kekal. Iman menjadi sebuah alat yang dipakai Tuhan untuk membuat orang-orang percaya menjadi percaya kepada Yesus sebagai juru selamat secara pribadi. ${ }^{32}$ Gaya hidup teladan yang dalam kedisiplinan seorang penginjil sangat penting, Yesus mempunyai gaya hidup sebagi penginjil sejati. Pikiran, perasaan, perkataan, perbuatan-Nya, seluruhnya sebagai teladan. Sikap hidup Kristiani yang benar-benar dijalankan dengan semestinya dapat Tuhan pakai untuk membuka hati orang-orang non Kristen terhadap Injil."

Komitmen seorang penginjil merupakan hal yang mutlak dimiliki oleh seorang pekabar Injil; komitmen kepada Kristus, komitmen kepada tujuan penginjilan, dan komitmen pada rencana penginjilan. Komitmen kepada Kristus berarti, pernyataan janji kepada Kristus yang harus dimiliki oleh seorang penginjil, karena Kristus adalah Sang Pemberi Amanat Agung untuk melaksanakan penginjilan ke seluruh dunia. Komitmen kepada Kristus membuat seorang penginjil menjadi tangguh. Komitmen yang dinyatakan adalah bersedia menderita seperti Kristus bahkan rela mati bagi Kristus, seperti pernyataan rasul Paulus: "Sebab aku yakin, bahwa penderitaan zaman sekarang ini tidak dapat dibandingkan dengan kemuliaan yang dinyatakan kepada kita" (Rm. 8:18).

\section{Kesaksian Hidup}

Kesaksian hidup merupakan salah satu metode penginjilan yang efektif dalam komunikasi Injil. Kesaksian hidup adalah berita kebenaran yang dapat dibaca orang.

\footnotetext{
${ }^{32}$ Gidion Gidion, "Studi Biblika Korelasi Teologi Paulus Dan Teologi Yakobus Tentang Iman Dan Perbuatan Iman," Shift Key: Jurnal Teologi dan Pelayanan 8, no. 2 (2018).
} 
Artinya kesaksian hidup sebagai berita Injil itu sendiri. Bukan hanya bersaksi dengan berita Injil yang disampaiakan scara verbal, tetapi gaya hidup, perbuatan dalam kehidupan sehari-hari itu sebagai isi kesaksian itu. Makna terang dan garam dunia, meskipun tidak bercerita tentang Yesus tetapi karena perbuatan kasih, kekudusan dan ketaatan kepada Tuhan itu menjadi cahaya kebenaran yang memancar dari dalam kehidupannya. Orang percaya yang telah diselamatkan memiliki tanggung jawab untuk hidup dalam kebenaran sesuai dengan tuntunan Roh Kudus. ${ }^{33}$

Hidup benar menjadi daya tarik yang efektif dalam penginjilan. Hidup Yesus telah menjadi sebuah contoh bagi dunia, dunia tidak mendapatinya melakukan dosa. Sehingga tidak dapat mendakwa diri-Nya sebagai orang berdosa. Inilah yang membuat dunia bungkam dimana terang itu mampu menerangi kegelapan. Kebenaran dalam Kristus menemplak dosa. Yesus menghardik para penyamun di Bait Allah, di mana ahli taurat dan orang Farisi mengotori rumah dosa menjadi sarang kejahatan. Betapa pentingnya penginjilan sebagai kesaksian hidup, dialami setiap orang percaya. Jika hidup orang percaya telah berkomitmen menjadi garam dan terang dunia maka ia akan sangat bermanfaat dalam pemenangan jiwa dari kesaksian hidupnya bukan sekadar kata-kata (Luk 22:71).

Yohanes bersaksi tentang Yesus, tetapi Yesus adalah Kabar Baik itu sendiri. Yohanes 1:7 mengatakan, bahwa ia datang sebagai saksi untuk memberi kesaksian tentang terang itu, supaya oleh dia semua orang menjadi percaya. Orang Kristen seharusnya bukan hanya menyampaikan kabar baik tetapi dirinya harus menjadi kabar baik itu sendiri, sebab Ia murid Kristus. Hidup benar menjadi salah satu cara efektif menjadi saksi Kristus. Sebab kebenaran itu memancar keluar dari kehidupan orang benar. Matius 5:14 menegaskan, bahwa orang Kristen adalah terang dunia. Kota yang terletak di atas gunung tidak mungkin tersembunyi.

Hidup Kristen memancarkan terang Kristus dari perbuatannya menjadi berkat. Yesus adalah utusan dari surga yang datang dengan tujuan untuk menebus dosa dunia. Menebus dari dosa dan menebus dari perbudakan Iblis. Penebusan oleh Kristus bukan hanya untuk manusia dapat bebas dari segala ketidakmampuannya menghadapi dosa, kedagingan dan kuasa Iblis, tetapi juga dikaruniakan Roh Kudus agar dapat mampu hidup benar, hidup dalam terang Firman Allah agar menjadi berkat bagi dunia. Yesus, sebagai utusan, menaati kehendak Bapa-Nya. Demikian pula murid Kristus, wajib menaati kehendak Kristus (Yoh. 20:21). Orang Kristen benar bukan karena usaha sendiri menjadi benar, tetapi karena dibenarkan oleh Kristus yang diyakininya dengan iman; meyakini bahwa orang percaya telah dibenarkan oleh Kristus, sehingga wajib hidup bertumbuh, berakar, berbuah dalam Kristus. Artinya, kehidupan dalam Kristus bukan melemparkan tangung jawab, melainkan berkomitmen untuk terus hidup dalam kekudusan.

\footnotetext{
${ }^{33}$ Susanto Dwiraharjo, "Persembahan Yang Hidup Sebagai Buah Dari Pembenaran Oleh Iman Menurut Roma 12:1-2,” PRUDENTIA: Jurnal Teologi dan Pendidikan Kristiani 1, no. 1 (2018): 1-6.
} 
Metode penginjilan kesaksian tidak dapat terpisahkan dengan mengabarkan Injil secara pribadi. Metode seperti ini sangatlah efektif dilaksanakan di semua budaya. Iswara mengemukakan,

Metode kesaksian (testimony) cenderung efektif di dalam semua budaya, khususnya di tengah-tengah budaya post-modern yang sedang dihadapi gereja masa kini. Cerita tentang pengalaman hidup sering menarik bagi orang lain, bahkan bagi orang-orang yang tidak suka atau tidak terbuka untuk membicarakan hal-hal keagamaan, kesaksian bahkan dapat mengatasi rintangan-rintangan intelektual. Seseorang biasa-nya menghentikan keterampilan berpikir kritisnya dan menurunkan kehati-hatian ketika mendengarkan sebuah cerita. ${ }^{34}$

Dengan demikian metode kesaksian bisa dilaksanakan di lingkungan keluarga, usaha, komunitas usahawan, komunitas mahasiswa, dan lainnya. Metode ini bisa akurat dan tepat sasaran dengan keteladanan.

Keteladanan memang sudah menjadi keharusan dimiliki pekabar Injil. Lebih lanjut Iswara berpendapat, "Bagi banyak orang Kristen, kehidupan saleh si penginjil adalah pembuka jalan yang efektif bagi kegiatan penginjilan. Di sini, demonstrasi cara hidup saleh dari orang-orang Kristen dipahami sebagai prapenginjilan."35 Dengan uraian di atas, maka dapat dipastikan bahwa keteladan bisa menjadi andalan dalam metode penginjilan seperti ini. Setidak-tidaknya keteladanan merupakan perintis atau pembuka jalan untuk orang lain menjadi respon dengan pemberitaan Injil. Sebagaimana dalam Kisah Para Rasul 2:46-47 dituliskan sikap keteladanan umat Tuhan disukai oleh semua orang yang menyebabkan bertambahnya orang percaya.

\section{KESIMPULAN}

Melalui kajian terhadap metode penginjilan Yesus menurut Injil Lukas, maka dapat disimpulkan bahwa melaksanakan aktivitas penginjilan, memerlukan sebuah metode sebagaiamana yang Yesus lakukan. Dalam penginjilan Yesus menggunakan berbagai metode agar berita Injil dapat dipahami oleh orang banyak. Penginjilan akan lebih efektif bahkan dapat tersampaikan dengan baik, apabila menggunakan metode yang benar dan yang bisa menyesuaikan dengan konteks. Lima metode yang dilakukan oleh Yesus dalam penginjilan kiranya juga bisa dipakai oleh orang-orang percaya juga para gembala di masa kini untuk memberitakan Injil kepada semua orang berdosa.

\section{REFERENSI}

Arifianto, Yonatan Alex, Reni Triposa, and Daniel Supriyadi. "Menerapkan Matius 5: 13 Tentang Garam Dunia Di Tengah Era Disrupsi." SHAMAYIM: Jurnal Teologi dan Pendidikan Kristiani 1, no. 1 (2020): 92-106.

Badai, Kristian, Kaleb Djeremod, and Frets Keriapy. "Penginjilan Sebagai Upaya Meneguhkan Keyakinan Keselamatan Anak." HARVESTER: Jurnal Teologi dan Kepemimpinan Kristen 5, no. 2 (2020): 120-134.

\footnotetext{
${ }^{34}$ Iswara Rintis Purwantara, Prapenginjilan (Yogyakarta: ANDI, 2012).

${ }^{35}$ Ibid., 47.
} 
Berutu, Meldayanti. "MAKNA PENDERITAAN YESUS DI KAYU SALIB (EKSEGETIS LUKAS 23: 33-43) DAN REFLEKSINYA BAGI UMAT KRISTEN MASA KINI." Areopagus: Jurnal Pendidikan Dan Teologi Kristen 18, no. 2 (2020): 76-83.

Bora, Lewi Nataniel. "Keserupaan Dengan Yesus Dalam Penderitaan, Kesengsaraan Dan Kematian-Nya." Manna Rafflesia 7, no. 1 (2020): 65-89.

Camerling, Yosua Feliciano, and Hengki Wijaya. "Misi Dan Kebangkitan Rohani: Implikasi Misi Allah Bagi Gereja." Jurnal Ilmiah Religiosity Entity Humanity (JIREH) 1, no. 1 (2019): 57-71.

Chresswell, John. Research Design: Qualitative and Quantitative Approaches. Thousand Ouks: Sage Publication, 1990.

Dwiraharjo, Susanto. “Kajian Eksegetikal Amanat Agung Menurut Matius 28 : 18-20." Jurnal Teologi Gracia Deo 1, no. 2 (2019): 56-73. http://sttbaptisjkt.ac.id/ejournal/index.php/graciadeo.

Dwiraharjo, Susanto. "Persembahan Yang Hidup Sebagai Buah Dari Pembenaran Oleh Iman Menurut Roma 12:1-2." PRUDENTIA: Jurnal Teologi dan Pendidikan Kristiani 1, no. 1 (2018): 1-6.

E.Boehlke, Robert. Sejarah Perkembangan Pikiran Dan Pendidikan Agama Kristen. Jakarta: BPK Gunung Mulia, 1991.

Fobia, B. "Yesus Dan Badai Laut" (1997).

Gidion, Gidion. "Studi Biblika Korelasi Teologi Paulus Dan Teologi Yakobus Tentang Iman Dan Perbuatan Iman." Shift Key: Jurnal Teologi dan Pelayanan 8, no. 2 (2018).

Hannas, Hannas, and Rinawaty Rinawaty. "Menerapkan Model Penginjilan Pada Masa Kini." KURIOS (Jurnal Teologi dan Pendidikan Agama Kristen) 5, no. 2 (2019): 175-189.

Harefa, Febriaman Lalaziduhu. "Menggunakan Konsep Inkarnasi Yesus Sebagai Model Penginjilan Multikultural." PASCA: Jurnal Teologi dan Pendidikan Agama Kristen 16, no. 1 (2020): 50-61.

Harming, Harming. "Metode Penginjilan Yesus Dalam Injil Yohanes 4: 1-42.” Evangelikal 1, no. 2 (2017): 162-169.

Hartono, Handreas. "Mengaktualisasikan Amanat Agung Matius 28: 19-20 Dalam Konteks Era Digital." KURIOS (Jurnal Teologi dan Pendidikan Agama Kristen) 4, no. 2 (2018): 157-166.

Heer, J.J de. Tafsiran Alkitab Injil Matius Pasal 1-22. Jakarta: BPK Gunung Mulia, 1991.

Illu, Jonidius. “PENGUSIRAN SETAN.” Phronesis: Jurnal Teologi dan Misi 3, no. 2 (2020): 158-169.

Kemdikbud. "Kamus Besar Bahasa Indonesia (KBBI)."

Kock, Heinz. Sang Guru Yang Baik. Yogyakarta: kanisius, 1986.

Purwantara, Iswara Rintis. Prapenginjilan. Yogyakarta: ANDI, 2012.

Purwoto, Paulus. "Makna Proselitisasi Di Masa Intertestamental Bagi Misi." EPIGRAPHE: Jurnal Teologi dan Pelayanan Kristiani 4, no. 2 (2020): 251-263.

Siahaya, Johannis. "Misi Dalam Doa Yesus Menurut Yohanes 17." Jurnal Teruna Bhakti 1, no. 2 (2019): 19-20. http://ejournal.stakterunabhakti.ac.id/index.php/teruna/issue/archive.

Sondopen, Dorce. "Relasi Antara Penginjilan Dan Pemuridan Untuk Pertumbuhan Gereja." Excelsis Deo: Jurnal Teologi, Misiologi, dan Pendidikan 3, no. 2 (2019): 95-105.

Sumiwi, Asih Rachmani Endang. "Peran Roh Kudus Dalam Kehidupan Orang Percaya Masa Kini." Jurnal Teologi Gracia Deo 1, no. 1 (2018): 23-31. 
Surjantoro, Bagus. Hati Misi. Yogyakarta: ANDI, 2006.

———. Misi Dari Dalam Krisis. Jakarta: Obor Mitra Indonesia, 2001.

Sutoyo, Daniel. PERAN ROH KUDUS DALAM PEMBERITAAN INJIL. Jurnal Antusias. Vol. 1. Shinkō Ongaku Shuppansha, 2011. Accessed April 27, 2017. http://www.sttintheos.ac.id/e-journal/index.php/antusias/article/view/1.

Tampenawas, Alfons Renaldo, Erna Ngala, and Maria Taliwuna. "Teladan Tuhan Yesus Menurut Injil Matius Dan Implementasinya Bagi Guru Kristen Masa Kini." EDULEAD: Journal of Christian Education and Leadership 1, no. 2 (2020): 214231.

Tanya, Edi. Gereja Dan Pendidikan Agama Kristen. Cianjur: STT Cipanas, 1999.

Tarigan, Bertha. "Konsep Doa Yesus Kristus Menurut Yohanes 17: 1-26." KERUGMA: Jurnal Teologi dan Pendidikan Agama Kristen 1, no. 2 (2019): 110-121.

Verwer, George. Melangkah Keluar Dari Kenyamanan Dunia. Yayasan Obor Mitra, 2001.

Widjaja, Fransiskus Irwan. Misiologi Antara Teori, Fakta Dan Pengalaman. 1st ed. Yogyakarta: Andi Offset, 2018.

Widjaja, Fransiskus Irwan, Daniel Ginting, and Sabar Manahan Hutagalung. "Teologi Misi Sebagai Teologi Amanat Agung." THRONOS: Jurnal Teologi Kristen 1, no. 1 (2019): 17-24.

Wongso, Peter. Tugas Gereja Masa Kini. Surabaya: Yakin, 1991. 